This item was submitted to Loughborough's Research Repository by the author.

Items in Figshare are protected by copyright, with all rights reserved, unless otherwise indicated.

\title{
The potential of thermoelectric generator in parallel hybrid vehicle applications
}

PLEASE CITE THE PUBLISHED VERSION

https://doi.org/10.4271/2017-01-0189

PUBLISHER

(C) SAE International

VERSION

AM (Accepted Manuscript)

\section{PUBLISHER STATEMENT}

This work is made available according to the conditions of the Creative Commons Attribution-NonCommercialNoDerivatives 4.0 International (CC BY-NC-ND 4.0) licence. Full details of this licence are available at: https://creativecommons.org/licenses/by-nc-nd/4.0/

\section{LICENCE}

CC BY-NC-ND 4.0

\section{REPOSITORY RECORD}

Lan, Song, C. Rouaud, Richard Stobart, Rui Chen, Zhijia Yang, and Dezong Zhao. 2017. "The Potential of Thermoelectric Generator in Parallel Hybrid Vehicle Applications”. figshare. https://hdl.handle.net/2134/24112. 


\section{The Potential of Thermoelectric Generator in Parallel Hybrid Vehicle Applications Author, co-author (Do NOT enter this information. It will be pulled from participant tab in MyTechZone) Affiliation (Do NOT enter this information. It will be pulled from participant tab in MyTechZone)}

\begin{abstract}
This paper reports on an investigation into the potential for a thermoelectric generator (TEG) to improve the fuel economy of a mild hybrid vehicle. A simulation model of a parallel hybrid vehicle equipped with a TEG in the exhaust system is presented. This model is made up by three sub-models: a parallel hybrid vehicle model, an exhaust model and a TEG model. The model is based on a quasistatic approach, which runs a fast and simple estimation of the fuel consumption and $\mathrm{CO}_{2}$ emissions. The model is validated against both experimental and published data. Using this model, the annual fuel saving, $\mathrm{CO}_{2}$ reduction and net present value (NPV) of the TEG's life time fuel saving are all investigated. The model is also used as a flexible tool for analysis of the sensitivity of vehicle fuel consumption to the TEG design parameters. The analysis results give an effective basis for optimization of the TEG design.
\end{abstract}

\section{Introduction}

Currently $14 \%$ of global greenhouse gas emissions are from transportation [1]. In order to reduce greenhouse gas emissions, a number of $\mathrm{CO}_{2}$ regulations for the road transport sector have been proposed around the world. In the EU, the law requires that by 2020 , the fleet average to be achieved by all new cars is 95 grams of $\mathrm{CO}_{2}$ per kilometer [2]. In the US, the Environment Protection Agency (EPA) and National Highway Traffic Safety Administration (NHTSA) raised the requirement for fuel economy of new passenger vehicles to 54.5 miles per gallon for the years 2017-2025 [3]. In Japan, the Top Runner program set $20.3 \mathrm{~km}$ per liter of fuel as the fuel efficiency target of passenger cars for 2020[4]. In the face of these internationally tightened requirements and regulations for passenger cars, the improvement of fuel economy and the development of alternative fuels has been a focus of research and design efforts.

Based on the typical energy flow path of an internal combustion engine (ICE), approximately one third of the energy is discharged by exhaust gas. Due to this great potential of waste heat recovery (WHR) in automotive, many efforts have been made in this field during the last few years, such as turbo-compounding [5], Rankine cycles [6], thermoelectric generators (TEG) [7], thermochemical recuperation (TCR) [8], and Stirling engines [9]. TEG has attracted substantial interest because of its advantage of silent operation, and compactness. Most of the current studies focus on the integration of TEG with conventional vehicles, using it to replace or relieve the alternator $[7,10]$. However, the use of a TEG in hybrids can be an especially desirable integration in the future where the number of hybrid vehicles is rising rapidly [11].

The main objectives of this paper:
- Using a simulation model of a TEG integrated in a hybrid vehicle to investigate the potential of fuel saving and $\mathrm{CO}_{2}$ reduction.

- Identify the main TEG design parameters' influence on fuel saving by means of a sensitivity analysis.

The body structure of this paper starts by highlighting advantages, limitations, and related research of the TEG integration with hybrid vehicle. The simulation model, which is made up by three submodels, is displayed in the section of model structure. The following section presents the model validation. In the section showing simulation results, the annual fuel saving, $\mathrm{CO}_{2}$ reduction and net present value (NPV) of the TEG's life time fuel saving are calculated based on simulation results. In the following section, a sensitivity analysis is carried out for the whole vehicle. Finally, the last section presents the main conclusion.

\section{Potential for TEG in Hybrid Vehicle}

The use of TEG in hybrid vehicles has many advantages over using it in conventional ICE vehicles. According to Roland Berger's report [11], the new vehicle sales market share of hybrid vehicles will increase significantly in the future, while the market share for the conventional ICE vehicles will shrink. Therefore, there is reason to believe that there will be a promising market for TEG integrated with hybrid vehicles. In a conventional ICE vehicle, the power generated by TEG can only be used when the electricity is needed in the vehicle. In hybrids, the electrical energy can be used directly for propulsion and the more energy recovered from the exhaust, the longer the motor can assist the engine. Vijayagopal et al [12] conducted a simulation analysis for the benefits of TEG varied with the type of vehicle: a conventional vehicle, a mild hybrid and a full hybrid. This study has shown that although the average power of TEG in conventional vehicle is higher than both two hybrid vehicles, the mild hybrid vehicle has the greatest fuel economy improvements because of its effective use of the recovered energy.

The main challenge and limitation for the integration of TEG with hybrid vehicle is the intermittent engine operation and lower total waste heat relative to a conventional vehicle. However, Kerstin et al [13] show that the total exhaust energy in hybrid vehicles is indeed less than in conventional vehicles, but because of high engine load, the exhaust temperature in hybrid operation is higher, which results in a high efficiency of TEG. Additionally, there are no conditions when either exhaust flow rate or temperature are low, and in general the number of operating points is fewer compared with engines in a conventional powertrain. Therefore, the design operating point is close to the maximum operating point and there is no need to bypass the exhaust flow. 


\section{Model Structure}

As can be seen in Figure 1, the simulation model of hybrid vehicle equipped with TEG is made up by three sub-models: a parallel hybrid vehicle model, an exhaust model and a TEG model. The parallel hybrid vehicle model is used to calculate the engine and motor's load and speed, fuel consumption and electrical energy consumption and generation based on the chosen driving cycle. The exhaust energy is computed at the exhaust model based on the engine speed and load. TEG model predicts the power output from recovering the exhaust energy and stores it in the battery. The energy balance of the whole system is controlled by the control system in the parallel hybrid vehicle model, using the equivalent consumption minimization strategy (ECMS) [14].

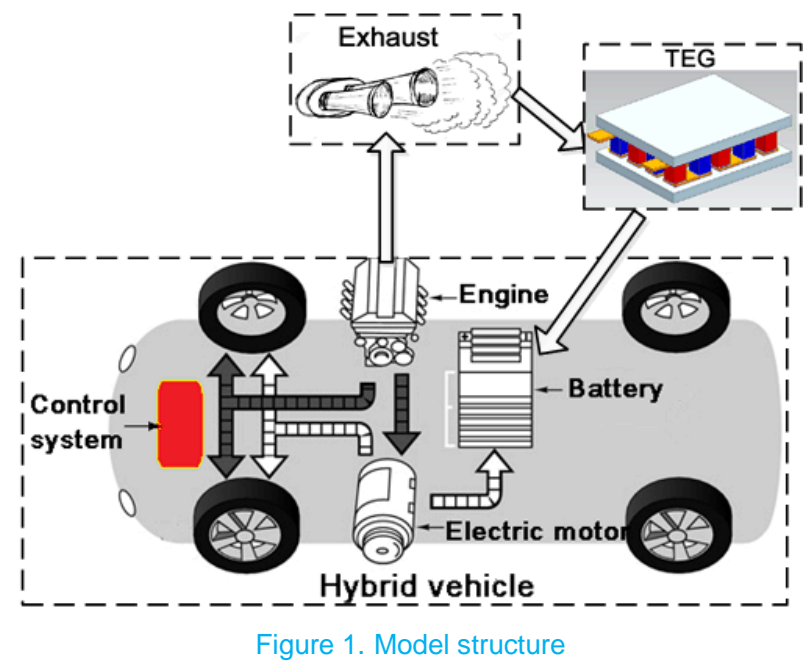

All the three models are built in the Quasi Static Simulation (QSS) toolbox [15] in Matlab/Simulink. The overview of the hybrid vehicle model, exhaust model and TEG model are all shown in Appendix A. The QSS toolbox can permit a fast and simple estimation of the fuel consumption and electrical energy consumption and generation using backward formulations. Thus, the performance of hybrid vehicle respectively with and without TEG can both be modelled and compared in the QSS model.

\section{Model Parameters}

The New European Driving Cycle (NEDC) is used as the driving cycle for the calculation of fuel consumption and $\mathrm{CO}_{2}$ emission. The D segment Audi A6 E-Tron is selected for the simulation study and its parameters are shown in Table 1. This selection is based on two principles:

- $\quad$ Large segment vehicles usually have a significant impact on the fleet average $\mathrm{CO}_{2}$ emission requirement for manufacturers.

- The Audi A6 has high popularity and space to absorb the incremental cost.

In this model, it is assumed that a TEG is installed after the catalystic convertor so that it has no influence on the catalystic reaction. The parameters of TEG system are listed in Table 2. The parameters for TEG system can be divided into three categories: heat exchanger parameters, thermoelectrical module (TEM) parameters, and coolant parameters. The parameter selection for respectively TEM and heat exchanger are based on references [16-17]. Figure 2 shows the

Page 2 of 10 structure of the TEG system. The size of TEG constrained to $0.3 \mathrm{~m} \times 0.24 \mathrm{~m} \times 0.1 \mathrm{~m}$ with TEMs on both sides of the hot side heat exchanger measuring $0.3 \mathrm{~m} \times 0.24 \mathrm{~m} \times 0.04 \mathrm{~m}$. 24 offset strip fins are used in hot side heat exchanger and they increase the total heat transfer area of each heat exchanger to around $0.7 \mathrm{~m}^{2}$. Based on reference [16], the average heat transfer coefficients for hot side and cold side heat exchanger are respectively 120 and $105 \mathrm{~W} / \mathrm{m}^{2} \mathrm{~K}$.

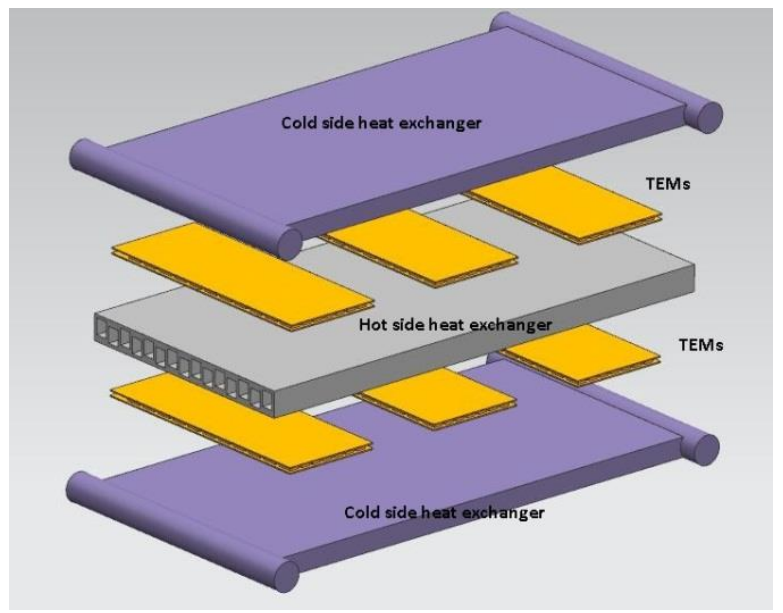

Figure 2 The structure of the TEG system

The simulation is based on high temperature thermoelectrical material Skutterudites materials working at a $Z T_{m}$ value of $0.7[16]$. Based on reference [17], the average thermal resistance of a Skutterudites TEM with the size of $16 \mathrm{~mm} \times 13 \mathrm{~m} \times 2 \mathrm{~mm}$ is $11 \mathrm{~K} / \mathrm{W}$. Since the Skutteruduite modules can be fabricated in different sizes and with different thermal resistances, instead of defining the number of TEMs, a fill factor $F$ is defined as

$$
F=\frac{n_{T E M} A_{T E M}}{2 A_{H X R}}
$$

where $n_{T E M}$ is number of TEMs in heat exchanger. $A_{T E M}$ is area of a TEM and $A_{H X R}$ is area of a heat exchanger surface.

Table 1. Specification for Audi A6 E-Tron

\begin{tabular}{|l|c|c|}
\hline Curb weight $\left(m_{v}\right)$ & $\mathrm{kg}$ & 1520 \\
\hline Drag coefficient $\left(D_{c}\right)$ & - & 0.29 \\
\hline Vehicle frontal area $\left(A_{f}\right)$ & $\mathrm{m}^{2}$ & 2.26 \\
\hline Tire radius $\left(R_{r}\right)$ & $\mathrm{m}$ & 0.326 \\
\hline Tire inertia $\left(I_{r}\right)$ & $\mathrm{kg} \cdot \mathrm{m}^{2}$ & 1.136 \\
\hline Engine Displacement $\left(V_{e}\right)$ & 1 & 2 \\
\hline Engine Type & - & Gasoline \\
\hline Engine inertia $\left(I_{e}\right)$ & $\mathrm{kg} \cdot \mathrm{m}^{2}$ & 0.2 \\
\hline Engine gear ratio $\left(r_{e}\right)$ & - & $13.75 / 7.698 / 5.336 / 3.994 /$ \\
\hline Motor gear ratio $\left(r_{m}\right)$ & - & $3.32-12.38$ \\
\hline Engine power $\left(P_{e}\right)$ & $\mathrm{kW}$ & 155 \\
\hline Motor power $\left(P_{m}\right)$ & $\mathrm{kW}$ & 40 \\
\hline Auxiliary power $\left(P_{a u}\right)$ & $\mathrm{kW}$ & 0.85 \\
\hline
\end{tabular}




$$
\dot{m}_{f}(t)=f_{i c}\left(T_{i c}(t), \omega_{i c}(t)\right)
$$

\begin{tabular}{|l|c|c|}
\hline TEG install position & \multicolumn{2}{|c|}{ after catalytic convertor } \\
\hline TEG weight $M_{T E G}$ & $\mathrm{~kg}$ & 20 \\
\hline Size of a heat exchanger & $m^{3}$ & $0.38 \times 0.24 \times 0.04$ \\
\hline Heat transfer area $A_{T E G}$ & $m^{2}$ & 0.7 \\
\hline Heat transfer coefficient of hot side heat & $\mathrm{W} / \mathrm{m}^{2} \mathrm{~K}$ & 120 \\
\hline Heat transfer coefficient of cold side heat & $\mathrm{W} / \mathrm{m}^{2} \mathrm{~K}$ & 105 \\
\hline Figure of merit ZT & - & 0.7 \\
\hline Size of a TEM & $m^{3}$ & $0.016 \times 0.013 \times 0.002$ \\
\hline Thermal resistance of a TEM $R_{T E M}$ & $\mathrm{~K} / \mathrm{W}$ & 11 \\
\hline Fill factor of TEMs in heat exchanger $\mathrm{F}$ & - & 0.52 \\
\hline Coolant mass flow rate $\dot{m}_{c o l}$ & $\mathrm{~kg} / \mathrm{s}$ & 0.1 \\
\hline Coolant temperature $T_{c o l}$ & $K$ & 293 \\
\hline
\end{tabular}

To tune and validate the model, test data is collected from engine laboratory and published papers. The data include dynamic exhaust data of a BMW 530i six-cylinder gasoline in NEDC cycle [10] and TEG test data taken from a CAT C6.6 ACERT diesel engine.

\section{Vehicle Model}

The vehicle model used here is a parallel hybrid vehicle model using the ECMS control strategy [14]. The diagram of the parallel hybrid powertrain considered is shown in Figure 3.

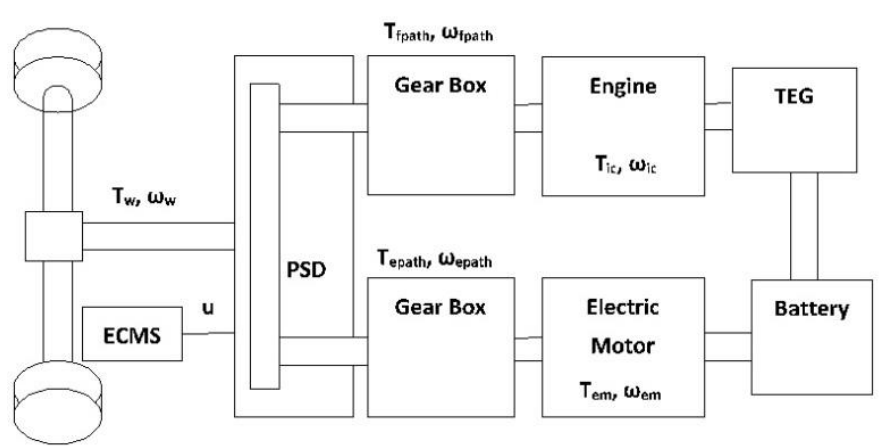

Figure 3. Diagram of the parallel hybrid vehicle

Based on the quasistatic approach, the wheel speed $\omega_{w}$ and torque $T_{w}$ of each instant are calculated so that they meet the driving cycle's demand. At the power split device (PSD), the basic relationship of the torque balance is

$$
T_{w}(t)=T_{\text {fpath }}(t)+T_{\text {epath }}(t)
$$

In the fuel path, based on the gear ratio of the engine $r_{e}$, the engine torque $T_{i c}(t)$ and speed $\omega_{i c}(t)$ can be calculated as follow:

$$
\begin{aligned}
& T_{i c}(t)=\frac{T_{\text {fpath }}(t)}{r_{e}} \\
& \omega_{i c}(t)=\omega_{w}(t) r_{e}
\end{aligned}
$$

The fuel consumption of the engine $\dot{m}_{f}(t)$ is calculated as a tabulated function of engine speed $\omega_{i c}$ and torque $T_{i c}$

Page 3 of 10

In the electrical path, the motor torque $T_{e m}(t)$ and speed $\omega_{e m}(t)$ can also be calculated according to the gear ratio of the gearbox $r_{m}$

$$
\begin{aligned}
& T_{\text {em }}(t)=\frac{T_{\text {epath }}(t)}{r_{m}} \\
& \omega_{\text {em }}(t)=\omega_{w}(t) r_{m}
\end{aligned}
$$

The output power of the battery $P_{b}(t)$ includes two parts: the output power of the motor $P_{e m}$ and the TEG $P_{T E G}$.

$$
P_{b}(t)=P_{e m}\left(T_{e m}(t), \omega_{e m}(t)\right)+P_{T E G}\left(T_{i c}(t), \omega_{i c}(t)\right)
$$

The ECMS regulates the torque distribution between the thermal and electrical paths with the torque split factor $u(t)$, which is defined as

$$
u(t)=\frac{T_{\text {epath }}(t)}{T_{w}(t)}
$$

When $u(t)=0$, it means that all the torque needed at the wheels is provided by the fuel path. When $u(t)=1$, it means all the torque needed at the wheel is provided by the electrical path or all the braking energy at the wheel is regenerated along the electrical path.

The ECMS finds control variable $\mathrm{u}(\mathrm{t})$ by minimizing the cost function $J(t, u)$, which is defined as

$$
J(t, u)=\Delta E_{f}(t, u)+s(t) \Delta E_{e}(t, u)
$$

$s(t)$ is the equivalence factor that is calculated online as a function of the current system status and some control parameters. The detail of calculation of $s(t)$ is presented in [14]. $\Delta E_{f}(t, u)$ and $\Delta E_{e}(t, u)$ are respectively the fuel energy and electrical energy used in interval $\Delta t$. Here $\Delta E_{e}(t, u)$ not only includes the energy consumed and generated by the electrical motor, but also includes the energy generated by the TEG.

$$
\Delta E_{f}(t, u)=\int_{t}^{t+\Delta t} H_{L H V} \dot{m}_{f}(\tau, u) d \tau
$$

$$
\Delta E_{e}(t, u)=\int_{t}^{t+\Delta t} P_{e m}(\tau, u) d \tau+\int_{t}^{t+\Delta t} P_{T E G}(\tau, u) d \tau
$$

$H_{L H V}$ is the lower heating value of the fuel.

\section{Exhaust Model}

The function of the exhaust model is to calculate the exhaust flow rate and temperature. The exhaust flow rate $\dot{m}_{\text {exh }}$ can be estimated based on the fuel consumption $\dot{m}_{f}(t)$ and air-fuel ratio $\lambda$, which can be expressed as

$$
\dot{m}_{e x h}(t)=(1+\lambda) \dot{m}_{f}(t)
$$

where air-fuel ratio $\lambda=14.7$. 
The power output of TEG is more sensitive to the exhaust temperature than the flow rate [18]. To capture the dynamic of exhaust temperature, the calculation of the exhaust temperature is based on the mean value engine model (MVEM) developed by Eriksson [19]. The core of the MVEM for exhaust temperature is to model the engine out temperature first and then model the temperature drop along the exhaust pipe.

A linear model is used for the engine out temperature $T_{\text {eout }}$

$$
T_{\text {eout }}=T_{\text {cyl. } .0}+\dot{m}_{\text {exh }} * K
$$

where $T_{c y l .0}$ and $K$ are tuning constants.

The temperature drop in the exhaust pipe $T_{\text {exh }}$ is expressed as:

$$
T_{\text {exh }}=T_{w}+\left(T_{\text {out }}-T_{w}\right) e^{-\frac{h A_{\text {pipe }}}{\dot{m}_{\text {exh }} c_{p h}}}
$$

$c_{p h}$ is the specific heat at constant pressure of the exhaust gas. $A_{\text {pipe }}$ is the pipe's surface area. $h$ is the heat transfer coefficient. Here $T_{\text {out }}$ can be the engine out temperature $T_{\text {eout }}$ but also can be the gas out temperature from any pipe. $T_{w}$ is the pipe wall temperature, which is determined by the following equation:

$$
\frac{d T_{w}}{d t} m_{w} c_{w}=\dot{Q}_{i}-\dot{Q}_{e}
$$

$c_{w}$ is the heat capacity of the pipe wall material, and $m_{w}$ is the pipe wall mass. $\dot{Q}_{i}$ and $\dot{Q}_{e}$ are respectively the heat transfer from the interior and exterior. The detail of calculation for $\dot{Q}_{i}, \dot{Q}_{e}$ and $h$ are presented in [19].

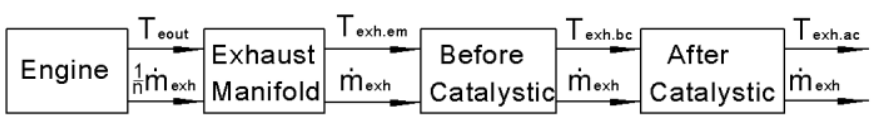

Figure 4. Structure of exhaust model

The model structure of this exhaust model is presented in Figure 4. Since here the TEG is installed downstream of the catalytic converter, the exhaust temperature model can be divided into four sub-models (Appendix A):

- Engine out temperature $T_{\text {eout }}$

- Temperature drop in the exhaust manifold $T_{\text {exh.em }}$

- Temperature drop before the catalystic convertor $T_{\text {exh.bc }}$

- Temperature drop after catalystic convertor $T_{\text {exh.ac }}$

In the three temperature drop sub-models, they have different pipe dimensions $A_{\text {pipe }}$, heat transfer coefficient $h$ and pipe wall mass $m_{w}$. Since the exhaust manifold collects the exhaust gases from multiple cylinders into one pipe; the exhaust flow rate in sub-model of temperature drop in the exhaust manifold also need to be divided by the number of the cylinders $n$.

\section{TEG Model}

As can be seen in Figure 5, a complete TEG system consists of thermoelectric modules (TEMs), heat exchangers, a heat source, a heat sink and connecting wires. In this TEG model, the exhaust gas of

Page 4 of 10 an ICE serves as the heat source and the engine coolant serves as a heat sink.

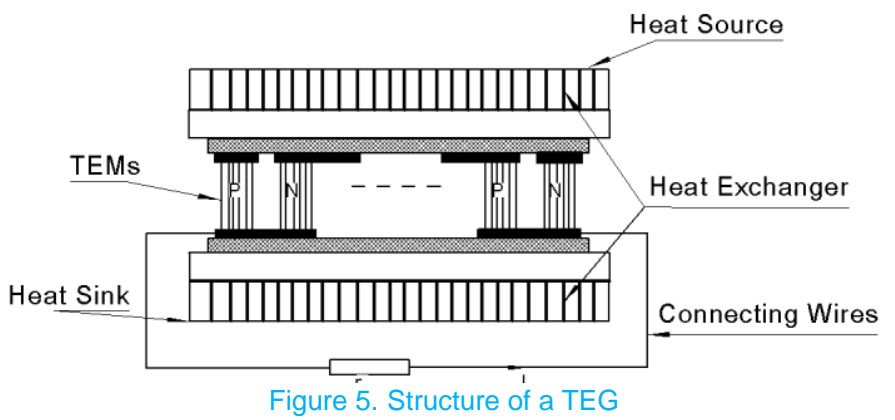

Here the TEG is a OD black box model. The inputs are exhaust temperature $T_{\text {exh }}$ and flow rate $\dot{m}_{\text {exh }}$, coolant temperature $T_{c o l}$ and flow rate $\dot{m}_{c o l}$. The output is maximum electrical power output $P_{T E G}$, achieved by matching the external load. The purpose of the TEG model is to reduce the complexity of a potentially detailed TEG model and instead to gain a vehicle perspective. Thus, the model only captures the influence of main design parameters, such as the size of TEG $A_{T E G}$, the heat transfer coefficients of heat exchangers $U_{h}$ and $U_{c}$ and the thermoelectrical material $\mathrm{ZT}_{m}$. The influence of backpressure is not considered by this OD TEG model.
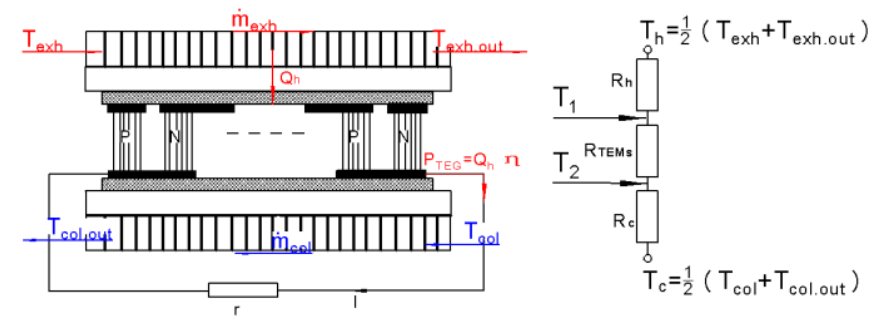

Figure 6. Heat flow across a TEG and TEG thermal resistance network

Since the TEG is symmetrical with respect to its height, only half of the domain is simulated. In Figure 6, the exhaust flow absorbed by TEG is defined as $Q_{h}$, which can be calculated as

$$
Q_{h}=c_{p h} \dot{m}_{e x h}\left(T_{e x h}-T_{\text {exh.out }}\right)
$$

$T_{\text {exh.out }}$ is the gas-out temperature of TEG; the expression of Esarte et al [20] is used:

$$
T_{\text {exh.out }}=T_{\text {exh }}-\left(T_{e x h}-T_{\text {col }}\right) \frac{1-e^{-N T U\left(1+C_{R}\right)}}{1+C_{R}}
$$

Where

$$
\begin{gathered}
N T U=\frac{1}{R_{T E G} \dot{m}_{e x h} c_{p h}} \\
C_{R}=\frac{\dot{m}_{e x h} c_{p h}}{\dot{m}_{c o l} c_{p c}}
\end{gathered}
$$

$\dot{m}_{c o l}$ and $c_{p c}$ are respectively the coolant mass flow rate and specific heat for coolant. $R_{T E G}$ is the total thermal resistance of the TEG. It can be seen that the heat transfer across the TEG $Q_{h}$ depends on the thermo-physical properties of the TEG and the hot and cold fluids. The coolant-out temperature can be expressed as 


$$
T_{\text {col.out }}=T_{\text {col }}+C_{R}\left(T_{\text {exh }}-T_{\text {col }}\right) \frac{1-e^{-N T U\left(1+C_{R}\right)}}{1+C_{R}}
$$

The total thermal resistance of a TEG $R_{T E G}$ is made up of the thermal resistance of respectively hot side and cold side heat exchanger $R_{h}, R_{c}$ and the total thermal resistance of the TEMs $R_{T E M S}$.

$$
R_{T E G}=R_{h}+R_{T E M S}+R_{c}
$$

The thermal resistance of the heat exchangers can be calculated as follow:

$$
\begin{gathered}
R_{\mathrm{h}}=\frac{1}{U_{h} A_{T E G}} \\
R_{C}=\frac{1}{U_{c} A_{T E G}}
\end{gathered}
$$

$U_{h}$ and $U_{c}$ are respectively the heat transfer coefficient of hot side and cold side heat exchangers. $A_{T E G}$ represents the heat transfer area of the heat exchanger.

All the TEMs are connected thermally in parallel, thus the total thermal resistance of the TEMs $R_{\text {TEMS }}$ is calculated as

$$
R_{T E M S}=\frac{R_{T E M}}{n_{T E M}}
$$

Substituting Equation (1) into Equation (25), the total thermal resistance of the TEMs can be expressed as:

$$
R_{\text {TEMS }}=\frac{R_{T E M} A_{T E M}}{2 F A_{H X R}}
$$

For both simplicity and generality, the power output is calculated using respectively the energy absorbed by the TEG $Q_{h}$ and TEMs' efficiency $\eta_{T E M S}$

$$
P_{T E G}=Q_{h} \eta_{T E M S}
$$

The idealized $\eta_{\text {TEMS }}$ can be written as [16]:

$$
\eta_{T E M s}=\left[\frac{m Z T_{1}}{Z T_{m}+m Z T_{1}+(m+1)^{2}}\right]\left[\frac{T_{1}-T_{2}}{T_{1}}\right]
$$

where $T_{1}$ and $T_{2}$ are respectively the hot and cold side temperature of the TEMs. $T_{m}=\left(T_{1}+T_{2}\right) / 2 . m=\frac{r_{L}}{r_{i n t}}$, which is the ratio of load electrical resistance $r_{L}$ and internal electrical resistance $r_{\text {int }}$.

A number of papers $[16,21,22]$ have recently reported the maximum power output of TEG is achieved when $m$ is slightly greater than 1 . When the thermal impedance matching is satisfied, $m$ can be expressed as:

$$
m=\sqrt{Z T_{m}+1}
$$

Substituting Equation (29) into Equation (28), the efficiency of TEMs at maximum power output $\eta_{\text {TEMs.mp }}$ can be expressed as

$$
\eta_{\text {TEMs.mp }}=\left[\frac{\sqrt{Z T_{m}+1}-1}{\sqrt{Z T_{m}+1}+\frac{T_{2}}{T_{1}}}\right]\left[\frac{T_{1}-T_{2}}{T_{1}}\right]
$$

The hot side and cold side temperature of TEMs can be expressed as follows [16]:

$$
\begin{aligned}
& T_{1}=T_{h}-\frac{R_{h}}{R_{h}+R_{c}+R_{\text {TEMS }}}\left(T_{h}-T_{c}\right) \\
& T_{2}=T_{c}+\frac{R_{c}}{R_{h}+R_{c}+R_{\text {TEMS }}}\left(T_{h}-T_{C}\right)
\end{aligned}
$$

where $T_{h}$ and $T_{c}$ are respectively the average temperature of the hot side and cold side heat exchanger.

$$
\begin{gathered}
T_{h}=\frac{T_{\text {exh }}+T_{\text {exh.out }}}{2} \\
T_{c}=\frac{T_{\text {col }}+T_{\text {col.out }}}{2}
\end{gathered}
$$

\section{Model Validation}

\section{Validation of the Exhaust Model}

The published dynamic exhaust data of BMW's 3L-gasoline engine in the NEDC [10] are used to tune and validate the exhaust model. When using BMW's published data, some assumptions are made. The mass flow rate data from BMW's six-cylinder engine to Audi A6's four-cylinder engine is simply extrapolated using a multiplication factor of 0.8 . The multiplication factor for exhaust gas temperature is 0.92 . The comparison of the extrapolated test data to the simulation results for the NEDC driving cycle is shown in Figure 7.

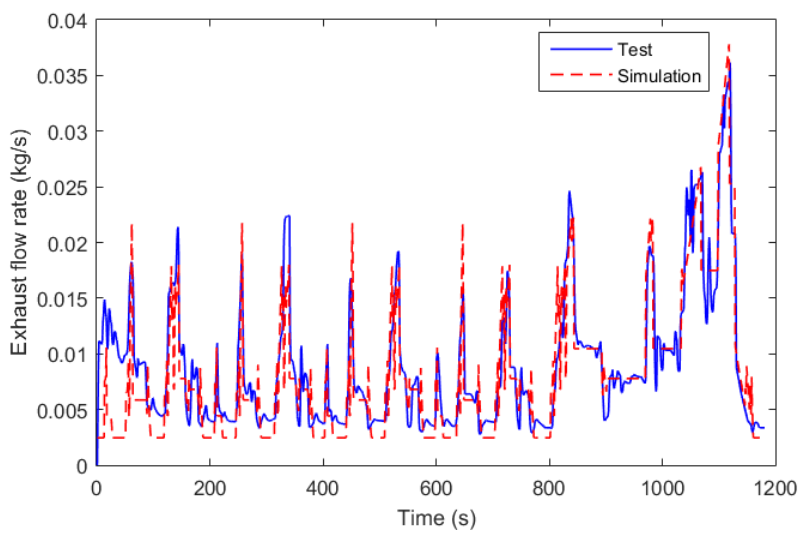

(a) Comparison of exhaust flow rate 


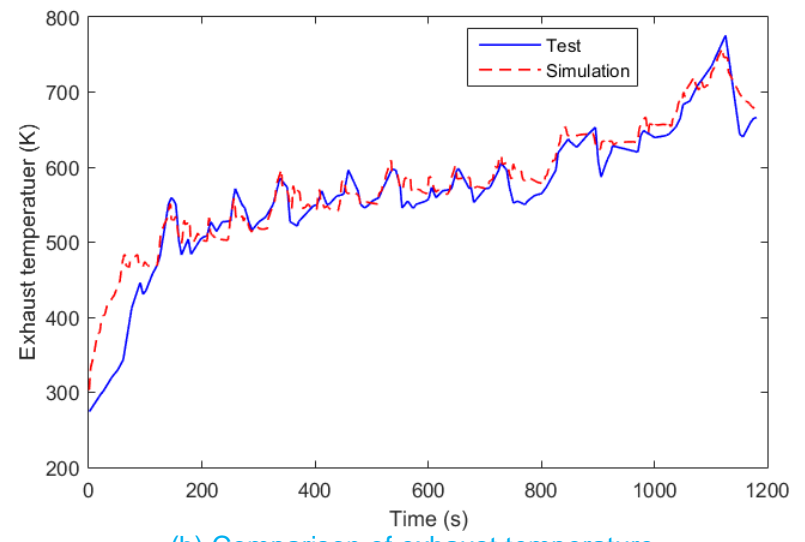

(b) Comparison of exhaust temperature

Figure 7. Simulation results of exhaust model and experiment data

The simulation result of flow rate corresponds well with the test results, with a mean absolute error around 5\%. For the exhaust temperature, errors at the beginning of the cycle can be explained by the unmodeled dynamics of heating and cooling effects and sensor dynamics. The variations in the temperature profile have a minor influence on the power output of the TEG [10]. Therefore, this exhaust model for this gasoline engine is validated and is used to provide inputs for the TEG model.

\section{Validation of the TEG Model}

The same apparatus as described in references $[19,23]$ is used for the TEG model validation. It can be seen in Figure 8 that a TEG with a plate-fin heat exchanger which contains four European Thermodynamics modules (GM250-127-28-10) is mounted in the EGR path of a CAT C6.6 ACERT diesel engine. All four TEMs are connected electrically in series. The cold side temperature of the TEG was maintained using chilled water from a laboratory recirculation chiller.

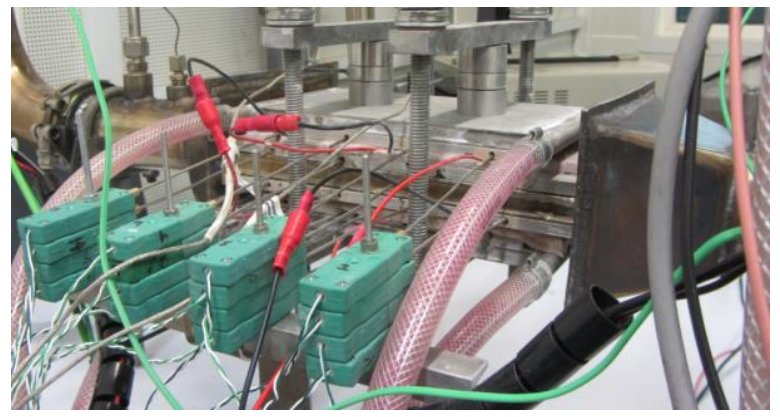

Figure 8. TEG installed in the EGR path for engine test

In order to control the hot side temperature of the modelled TEMs to within the limit of the module specifications, the authors elected to use a 30\% torque NRTC (Non-Road Transient Cycle) on the C6.6 engine. The chiller is set as a fixed temperature $20^{\circ} \mathrm{C}$ and its mass flow rate $0.1 \mathrm{~kg} / \mathrm{s}$. The load electric resistance is set close to the modules' resistances. The comparison of the test data with the simulation results is presented in Figure 9. The simulation results correspond well with the measurement results. Since the $Z T_{m}$ in the TEG model is set as constant in the model while in reality it is temperature-dependent, this results in an overestimation of power at low temperature and an underestimation at high temperature. However, the errors can be further diminished when accumulating the overall power output of TEG in a driving cycle. Thus, this OD black box TEG model can provide a reasonable accuracy.

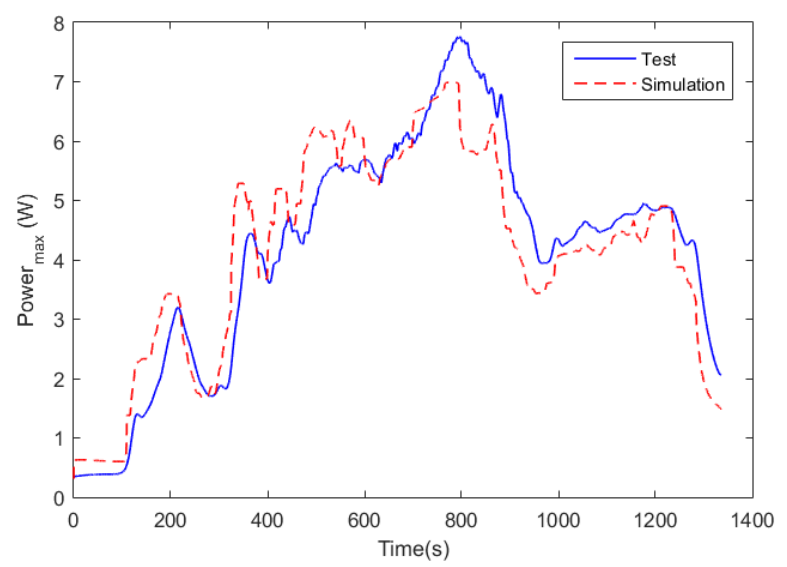

Figure 9. Simulation results of TEG model and experimental data

\section{Validation of the ECMS}

Control parameters of the ECMS are selected based on the data listed in Table 1 and Table 2. The performance of the ECMS for this TEG hybrid vehicle in the NEDC cycle is validated throughout the range of torque distribution and battery state-of-charge(SOC), which are shown in Figure 10 and Figure 11. The ECMS distributes the torque between the engine and motor and maintains the balance of SOC with no SOC variations at the end of the NEDC cycle.

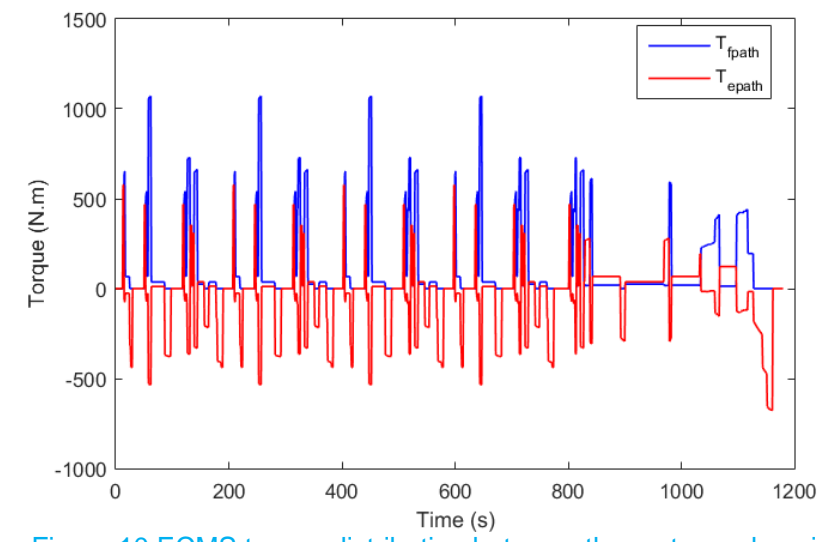

Figure 10 ECMS torque distribution between the motor and engine

Page 6 of 10 


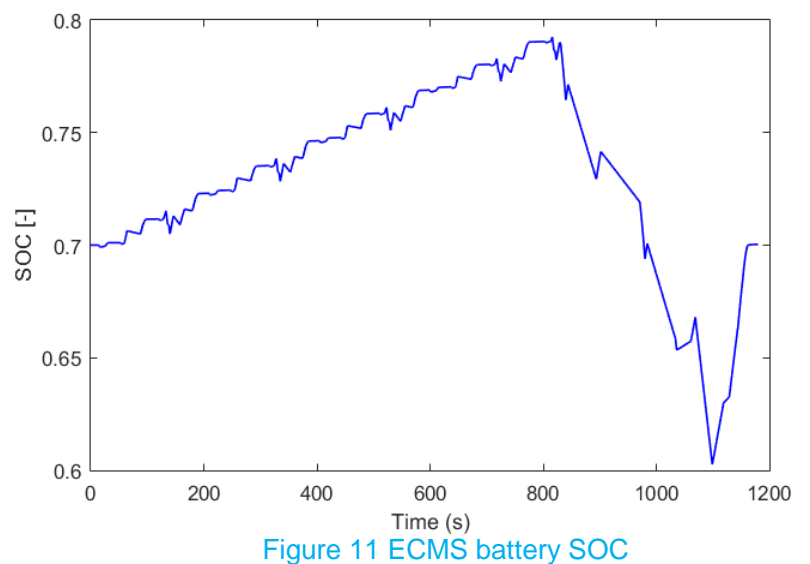

Simulation Result

In this section of the paper, the simulation results are presented. The power output of the TEG in NEDC is shown in Figure 12. During the urban section of the cycle the TEG power output averages $80 \mathrm{~W}$ and increases to $200 \mathrm{~W}$ over the extra-urban cycle. The peak power output reaches $450 \mathrm{~W}$ in the extra-urban cycle.

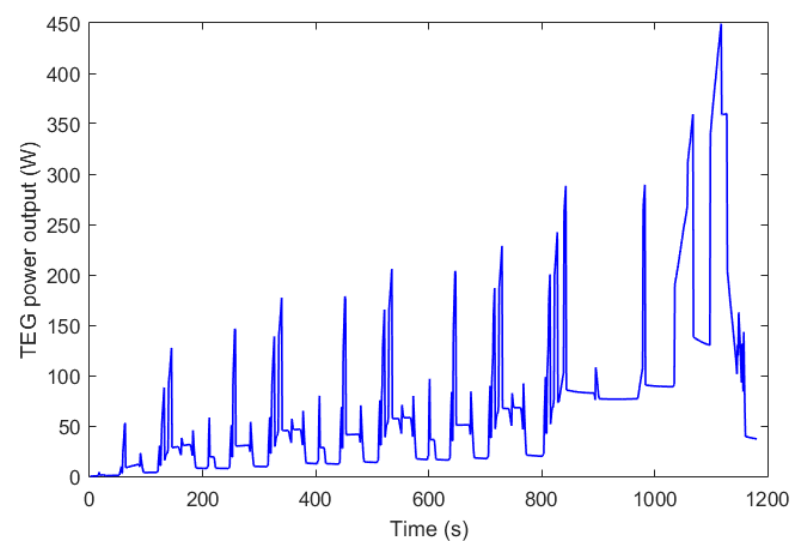

Figure 12 Power output of TEG in NEDC cycle

The fuel economy and $\mathrm{CO}_{2}$ reduction due to the TEG in hybrid vehicle operation is compared with hybrid without TEG and the results shown in Table 3. In order to make them comparable, the ECMS constrains the initial and terminal SOC for both hybrid vehicles as 0.7 and no SOC variations at the end of the cycle. The fuel saving due to the TEG is $0.15 \mathrm{~L} / 100 \mathrm{~km}(3.4 \%)$ and the $\mathrm{CO}_{2}$ reduction is $3.4 \mathrm{~g} / \mathrm{km}(3.3 \%)$.

Table 3. Fuel economy and $\mathrm{CO}_{2}$ reduction

\begin{tabular}{|l|c|c|c|c|}
\hline & $\begin{array}{l}\text { Hybrid } \\
\text { vehicle }\end{array}$ & $\begin{array}{c}\text { Hybrid } \\
\text { vehicle } \\
\text { (TEG) }\end{array}$ & Fuel saving & $\begin{array}{c}\mathrm{CO}_{2} \\
\text { reduction }\end{array}$ \\
\cline { 1 - 4 } $\begin{array}{l}\text { Fuel consumption } \\
(\mathrm{L} / 100 \mathrm{~km})\end{array}$ & 4.39 & 4.24 & $\begin{array}{c}0.15 \mathrm{~L} / 100 \mathrm{~km} \\
(3.4 \%)\end{array}$ & $\begin{array}{c}3.4 \mathrm{~g} / \mathrm{km} \\
(3.3 \%)\end{array}$ \\
\cline { 1 - 3 } $\begin{array}{l}\mathrm{CO}_{2} \text { emission } \\
(\mathrm{g} / \mathrm{km})\end{array}$ & 103 & 99.6 & \multicolumn{2}{|c}{} \\
\hline
\end{tabular}

According to Roland Berger's report [11], the annual driving distance for a passenger car is $11,600 \mathrm{~km}$. The current gasoline price is $1.6 € / \mathrm{L}$. Based on these an annual fuel saving and $\mathrm{CO}_{2}$ reduction of this TEG Page 7 of 10 hybrid vehicle are calculated in Table 4. It is assumed that the TEG life time is 15 years and $7 \%$ discount rate. The net present value (NPV) of the TEG's life time fuel savings is calculated [12].

$$
N . P . V=\sum_{m=1}^{m=15} P . V_{m}
$$

$P . V_{m}$ is the present value of saving of the nth year and it can be expressed as:

$$
P . V_{m}=F \cdot V_{m}(1+d)^{-m}
$$

$F . V_{m}=25.9 €$, which is the future fuel saving and here it is equal to the annual fuel saving. $d=7 \%$, which is the discount rate.

Table 4. Annual fuel saving and $\mathrm{CO}_{2}$ reduction

\begin{tabular}{|c|c|}
\hline Annual fuel saving for TEG hybrid vehicle $[\mathrm{L}]$ & $11600 \times \frac{0.15}{100}=17.4$ \\
\hline Annual fuel saving for TEG hybrid vehicle $[€]$ & $17.4 \times 1.6=27.8$ \\
\hline Annual $\mathrm{CO}_{2}$ reduction for TEG hybrid vehicle $[\mathrm{g}]$ & $11600 \times 3.4=39,440$ \\
\hline N.P.V $[€]$ & $\sum_{m=1}^{m=15} P . V_{m}=253$ \\
\hline
\end{tabular}

As can be seen in Table 4, for the customers, the average fuel saving is $27.8 €$ while the NPV of the fuel saving over the vehicle lifetime is $253 €$. For the original equipment manufacturer (OEM), the annual $\mathrm{CO}_{2}$ reduction is $39,4 \mathrm{~kg}$, which helps to reduce the $\mathrm{CO}_{2}$ emission target for the vehicle fleet. The economic benefit potential of TEG integrated with hybrid is large for both customers and OEMs.

\section{Sensitivity Analysis}

A sensitivity analysis is essential to identify which TEG design parameters have the greatest impact on the fuel saving. The core information of this sensitivity analysis is that the input variables are perturbed slightly, and the corresponding change in the outputs is reported as a percentage change in the outputs [24]. In a previous study [18], the sensitivity analysis of TEG is only on a standalone model. Here it is analysed from a vehicle system point of view.

The process of sensitivity analysis is conducted as follows. The size of the heat exchanger and the size of TEM and its thermal resistance are fixed to form a baseline. The remaining parameters are selected as TEG. The TEG parameters given in Table 2 and fuel consumption of working at these parameters are used as the base values. One TEG variable is increased $20 \%$ around its base value, while all other variables are fixed at their respective base values. Then the fuel consumption is computed and recorded as the percentage changing above or below the base values C(\%), which can be expressed as follow:

$$
\mathrm{C}(\%)=\frac{\dot{m}_{f . c}-\dot{m}_{f . b}}{\dot{m}_{f . b}} \times 100 \%
$$


Where $\dot{m}_{f . c}$ is fuel consumption of $20 \%$ increase in a variable and $\dot{m}_{f . b}$ is the baseline fuel consumption.

This process is repeated for every TEG variable. Each time, the ECMS algorithm ensures that there are no SOC variations. The sensitivity analysis results are presented in both Table 5 and Figure 13.

Table 5. Sensitivity analysis results on the fuel consumption

\begin{tabular}{|l|c|}
\hline Input Parameters & $C(\%)$ \\
\hline TEG's weight $M_{T E G}$ & +0.0776 \\
\hline Heat transfer coefficient of hot side heat exchanger $U_{h}$ & -0.0588 \\
\hline Heat transfer coefficient of cold side heat exchanger $U_{c}$ & -0.0752 \\
\hline Heat transfer area A & -0.2869 \\
\hline Figure of merit ZT & -0.3245 \\
\hline Fill factor of TEMs in heat exchanger F & -0.2069 \\
\hline Coolant mass flow rate $\dot{m}_{c o l}$ & -0.0092 \\
\hline Coolant temperature $T_{c o l}$ & +0.0095 \\
\hline
\end{tabular}

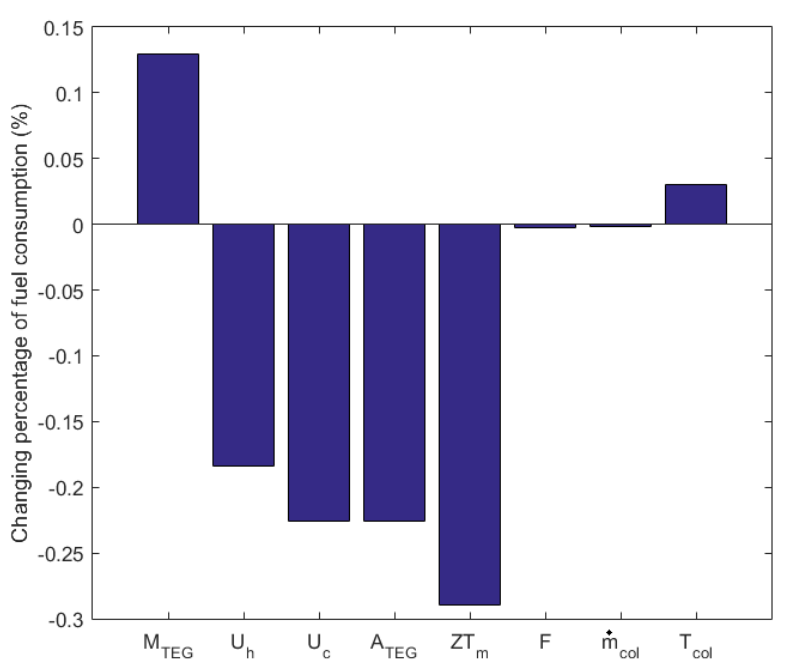

Figure 13 Sensitivity analysis results on the fuel consumption

It can be seen that the fuel consumption is most sensitive to the thermoelectric material properties ( $\mathrm{Z} T_{m}$ value). For the heat transfer coefficient $\left(U_{h}\right.$ and $\left.U_{c}\right)$, heat transfer area $\left(A_{T E G}\right)$ and added weight of TEG, they both influence the fuel saving at a moderate level. On the other hand, fill factor of TEMs in heat exchanger $(\mathrm{F})$, coolant temperature $\left(T_{c o l}\right)$ and its flow rate $\dot{m}_{c o l}$ only have a minor effect on the fuel saving. The negligible effect of the fill factor can be explained by the fact that the $\mathrm{F}$ is already close to its optimal value in current TEG systems. The sensitivity analysis results can be used as guidance for the further fabrication and optimization of the TEG.

\section{Conclusion}

A model of the TEG integrated with a parallel hybrid vehicle has been developed to investigate the potential of the TEG to reduce $\mathrm{CO}_{2}$ emissions. The model has been validated against both experimental Page 8 of 10 and published data. The simulation results show that for the NEDC cycle, a $3.4 \%$ fuel saving with $80-200 \mathrm{~W}$ energy recovered from the TEG. The annual $\mathrm{CO}_{2}$ reduction is $39,4 \mathrm{~kg}$. The NPV of the TEG's life time fuel saving is $253 €$. Thus, if the cost of the TEG to the OEM is less than $200 €$ then the installation of a TEG represents a significant gain for the customers.

A sensitivity analysis reveals the priority order of the parameters to achieve maximum fuel saving and offer guidance to the further fabrication and optimization of the TEG. When designing a TEG, the priority is to choose the material with the maximum $\mathrm{ZT}_{m}$ available in the desired temperature range. Then, there should be an optimisation of the design of the TEG structure with both large heat transfer area and heat transfer coefficient but still lightweight. After that, an optimisation of fill factor of TEMs in heat exchange is also necessary. Last in the priority order is maintaining the coolant temperature at low value and high flow rate.

\section{References}

1. Change, Intergovernmental Panel on Climate. Climate Change 2014: Mitigation of Climate Change. Vol. 3: Cambridge University Press, 2015.

2. Thiel, Christian, Adolfo Perujo, and Arnaud Mercier. "Cost and Co 2 Aspects of Future Vehicle Options in Europe under New Energy Policy Scenarios." Energy policy 38, no. 11 (2010): 7142-51.

3. Fabrizio Arena, Luca Mezzana. "The Automotive $\mathrm{CO}_{2}$ Emissions Challenge: 2020 Regulatory Scenario for Passenger Cars." Arthur D. Little http://www.adlittle.com/viewpoints.html?\&view=664.

4. Arima, Jun. "Top Runner Program." In Workshop on Best Practices in Policies and Measures, vol. 11, p. 13. 2000.

5. Aghaali, Habib, and Hans-Erik Ångström. "A review of turbocompounding as a waste heat recovery system for internal combustion engines." Renewable and Sustainable Energy Reviews 49 (2015): 813-824.

6. Feru, Emanuel, Frank Willems, Chepa Rojer, Bram de Jager, and Maarten Steinbuch. "Heat exchanger modeling and identification for control of waste heat recovery systems in diesel engines." In 2013 American Control Conference, pp. 2860-2865. IEEE, 2013.

7. Stobart, Richard K., Anusha Wijewardane, and Chris Allen. The potential for thermo-electric devices in passenger vehicle applications. No. 2010-01-0833. SAE Technical Paper, 2010.

8. Kirillov, V. A., A. B. Shigarov, N. A. Kuzin, V. V. Kireenkov, Yu I. Amosov, A. V. Samoilov, and V. A. Burtsev.

"Thermochemical conversion of fuels into hydrogen-containing gas using recuperative heat of internal combustion engines." Theoretical Foundations of Chemical Engineering 47, no. 5 (2013): 524-537.

9. Aladayleh, Wail, and Ali Alahmer. "Recovery of exhaust waste heat for ICE using the beta type Stirling engine." Journal of Energy 2015 (2015).

10. LaGrandeur, John, D. Crane, S. Hung, B. Mazar, and A. Eder. "Automotive waste heat conversion to electric power using skutterudite, TAGS, PbTe and BiTe." In 2006 25th International Conference on Thermoelectrics, pp. 343-348. IEEE, 2006.

11. SLOT, ARNOUD VAN DER. "Study Integrated Fuels and Vehicles Roadmap 2030+." Roland Berger. 
12. Vijayagopal, Ram, and Aymeric Rousseau. Impact of TEGs on the Fuel Economy of Conventional and Hybrid Vehicles. No. 2015-01-1712. SAE Technical Paper, 2015.

13. Oetringer, Kerstin, Martin Kober, and Mirko Klein Altstedde. "Upgrading hybrid-vehicles with a Thermoelectric Generator." In Ecological Vehicles and Renewable Energies (EVER), 2014 Ninth International Conference on, pp. 1-5. IEEE, 2014.

14. Sciarretta, Antonio, Michael Back, and Lino Guzzella. "Optimal control of parallel hybrid electric vehicles." IEEE Transactions on control systems technology 12, no. 3 (2004): 352-363.

15. Guzzella, L., and A. Amstutz. "The QSS Toolbox Manual," IMRT Swiss Federal Institute of Technology Zurich." Ready from WWW: http://www. imrt. ethz. ch/research/qss (2005).

16. LeBlanc, Saniya, Shannon K. Yee, Matthew L. Scullin, Chris Dames, and Kenneth E. Goodson. "Material and manufacturing cost considerations for thermoelectrics." Renewable and Sustainable Energy Reviews 32 (2014): 313-327.

17. García-Cañadas, Jorge, Anthony V. Powell, Andreas Kaltzoglou, Paz Vaqueiro, and Gao Min. "Fabrication and evaluation of a skutterudite-based thermoelectric module for high-temperature applications." Journal of electronic materials 42, no. 7 (2013): $1369-1374$

18. Lan, Song, Zhijia Yang, Richard Stobart, and Edward Winward. The Influence of Thermoelectric Materials and Operation Conditions on the Performance of Thermoelectric Generators for Automotive. No. 2016-01-0219. SAE Technical Paper, 2016.

19. Eriksson, Lars. Mean value models for exhaust system temperatures. No. 2002-01-0374. SAE Technical Paper, 2002.

20. Esarte, J., G. Min, and D. M. Rowe. "Modelling heat exchangers for thermoelectric generators." Journal of Power Sources 93, no. 1 (2001): 72-76.

21. Yazawa, Kazuaki, and Ali Shakouri. "Optimization of power and efficiency of thermoelectric devices with asymmetric thermal contacts." Journal of Applied Physics 111, no. 2 (2012): 024509 .

22. Apertet, Y., H. Ouerdane, C. Goupil, and Ph Lecoeur. "Influence of thermal environment on optimal working conditions of thermoelectric generators." Journal of Applied Physics 116, no. 14 (2014): 144901.

23. Yang, Zhijia, Edward Winward, Song Lan, and Richard Stobart. Optimization of the Number of Thermoelectric Modules in a Thermoelectric Generator for a Specific Engine Drive Cycle. No. 2016-01-0232. SAE Technical Paper, 2016.

24. Principe, Jose C., Neil R. Euliano, and W. Curt Lefebvre. Neural and adaptive systems: fundamentals through simulations with CD-ROM. John Wiley \& Sons, Inc., 1999.

\section{Contact Information}

Song Lan

$\underline{\text { s.lan@lboro.ac.uk }}$

Rui Chen

$\underline{\text { r.chen@1boro.ac.uk }}$

\section{Acknowledgments}

The authors would like to gratefully acknowledge the UK Engineering and Physical Sciences Research Council (EPSRC) and China Scholarship Council (CSC) for funding this research work.

\begin{tabular}{lc} 
Abbreviations & \\
DISI & Direct Injection Spark Ignition \\
EGR & Exhaust Gas Recirculation \\
ECMS & Equivalent Consumption Minimization Strategy \\
ICE & Internal Combustion Engine \\
OEM & Original Equipment Manufacturer \\
NEDC & New European Driving Cycle \\
NRTC & Non-Road Transient Cycle \\
NPV & Net Present Value \\
QSS & Quasi Static Simulation \\
TCR & Thermochemical Recuperation \\
TEM & Thermoelectric Module \\
TEG & Waste Heat Recovery \\
\hline
\end{tabular}

Page 9 of 10 


\section{Appendix A}

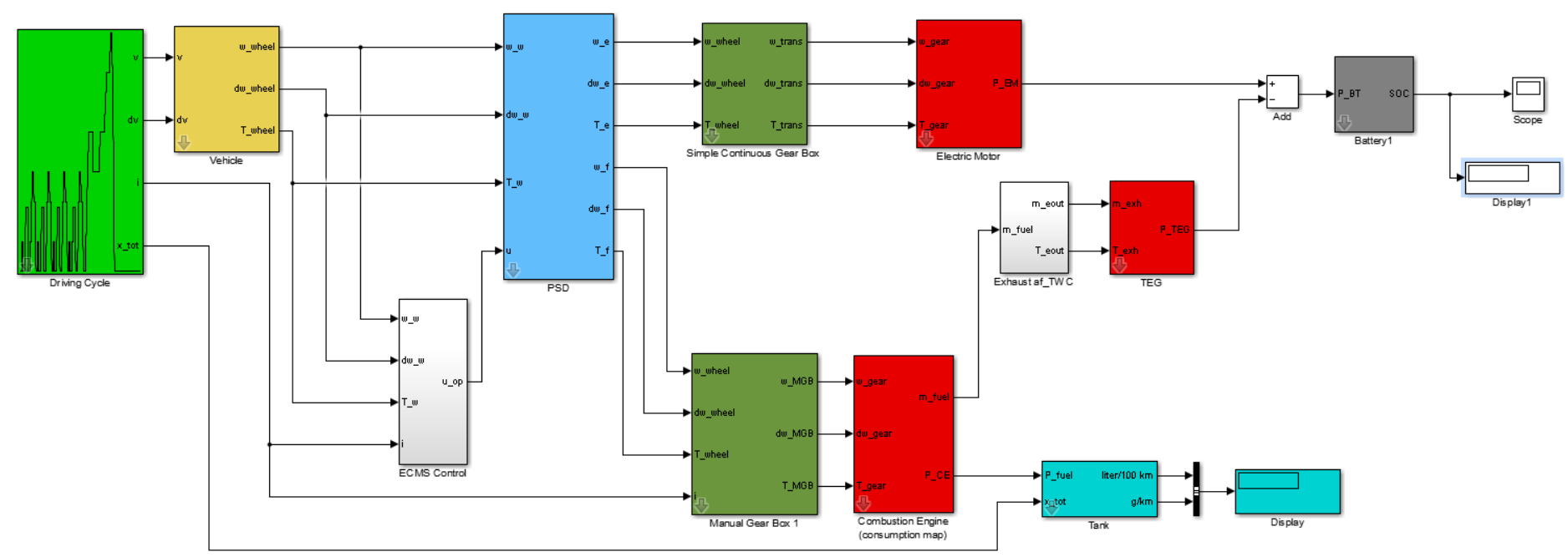

Figure A. The overview of the TEG hybrid model

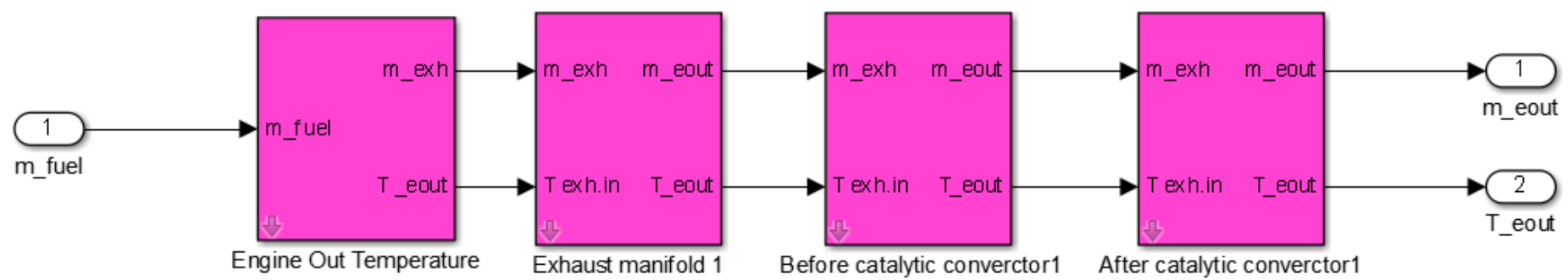

Figure B. The overview of the Exhaust model

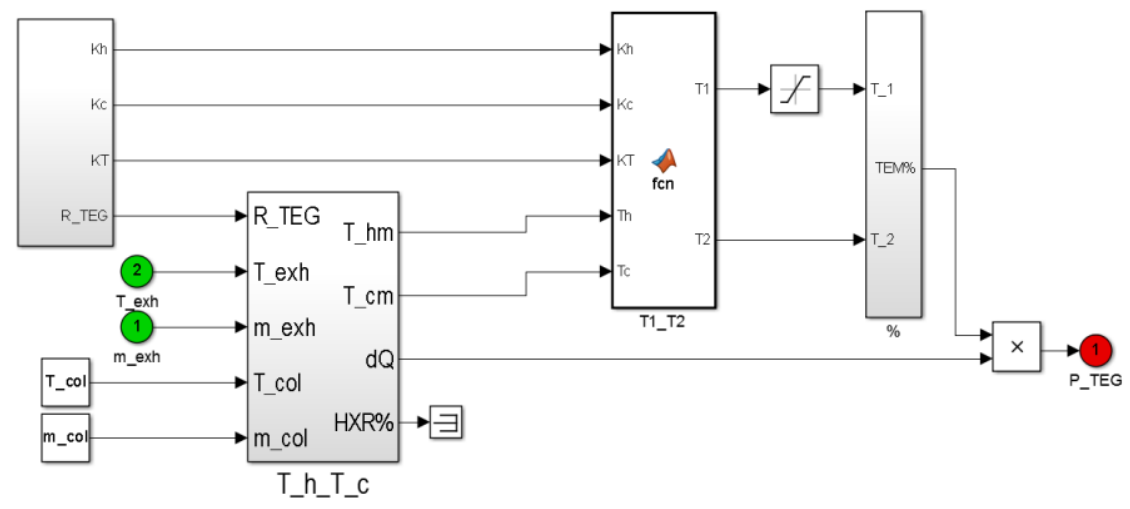

Figure C. The overview of the TEG model

Page 10 of 10 